\title{
Resenha
}

\section{CIÊNCIA OU PRUDÊNCIA NO USO DA TÉCNICA NA ENGENHARIA GENÉTICA}

Livro: SANDEL, Michael J. Contra a perfeição: Ética na era da engenharia genetica. (trad. Ana Carolina Mesquita). Rio de Janeiro: Civilização Brasileira, 2013, 160 páginas.

Quétlin Nicole Meurer

Contra a Perfeição: Ética na era da engenharia genética é fruto de vários estudos e principalmente da participação do autor no Conselho de Bioética criado pelo presidente George w. Bush em 2001 com o intuito de refletir em torno de temas controversos ligados à engenharia genética. Por isso, o autor explora dilemas morais relacionados à busca do ser humano em aperfeiçoar a espécie.

Enquanto em sua obra Justiça: o que é fazer a coisa certa? enfoca questões como o suicídio assistido, o aborto, a barriga de aluguel e a utilização de células tronco, este texto aborda especificamente a questão do melhoramento humano. Em ambos, entretanto, firma sua posição no sentido de que as pessoas não podem se apoiar em determinados pressupostos de cunho pessoal de modo a escolher o fim de suas vidas sem revisar a dependência que possuem em relação a laços comunitários.

No mesmo sentido de outro livro seu $O$ que o dinheiro não compra? Os limites morais do mercado, nesta obra fica implícita a sua discordância em relação ao liberalismo e, consequentemente, ao Estado mínimo, entendendo ser necessário limites morais para o mercado de consumo. Pontua de forma subentendida a necessidade de alguma espécie de regulamentação na vida pública e nas relações interpessoais, a fim de que determinados bens não possam ser vendidos, devendo, sim, ser regulados por valores da moral.

\footnotetext{
* Mestranda em Filosofia pela Universidade de Caxias do Sul (UCS). E-mail: quetlin.meurer@inss.gov.br
}

\begin{tabular}{|c|c|c|c|c|c|}
\hline intuitio & $\begin{array}{c}\text { ISSN } \\
1983-4012\end{array}$ & Porto Alegre & Vol.8 $-\mathrm{N}^{\circ} .1$ & $\begin{array}{c}\text { Junho } \\
2015\end{array}$ & p.317-324 \\
\hline
\end{tabular}


Reportando-nos novamente de forma específica a obra em questão, a mesma é dividida em cinco capítulos: a ética do melhoramento; atletas biônicos; filhos projetados, pais projetistas; a nova e a velha eugenia e, domínio e talento, além do epílogo. Também conta com notas e índice remissivo, o que permite melhor manuseio da obra.

O primeiro capítulo é aberto com reportagens de jornais, como Washington Post, que relatam histórias sobre escolhas genéticas. $\mathrm{O}$ autor se pergunta: o que há exatamente de errado em gerar um filho que seja um gêmeo idêntico do pai ou da mãe, de um irmão mais velho que morreu tragicamente ou, até mesmo, de um cientista, um atleta ou uma celebridade admirada? Discute, a partir de então, o porquê de nos sentirmos perturbados com essa ideia. O problema inicial estaria na falta de autonomia dessas crianças que nasceriam pré-determinadas, ou seja, não inteiramente livres. Entretanto, posteriormente, desfaz esse argumento uma vez que mesmo não havendo um projetista (nesse caso os pais) ninguém escolhe sua herança genética. No entanto, mesmo assim, o fato de crianças poderem ser geradas sobe encomenda nos causa uma imensa inquietude moral. Segundo o autor, existem exemplos de biotecnologia desenhados no horizonte: melhoramento muscular, da memória, da altura e escolha do sexo, sendo eles uma escolha de consumo. Então, apesar de todos os melhoramentos genéticos começarem na tentativa de prevenir uma doença ou um distúrbio genético, hoje são instrumentos de melhoria da espécie. A diferença, portanto, entre curar e melhorar se torna de cunho moral. Logicamente é sabido que, quando a ciência avança mais depressa do que a compreensão moral, a humanidade luta para articular seu mal-estar com conceitos de justiça, autonomia e direitos humanos. Porém, nos parece, assim como para o autor, que o melhoramento de músculos em atletas para torná-los mais competitivos, por exemplo, não está relacionado com uma questão de justiça. Já existem atletas mais aptos geneticamente simplesmente por herança genética e se esse fosse o principal argumento, se essas modificações estivessem disponíveis a todos, não haveria problemas a serem discutidos. Isso, no entanto, não acontece. A questão de ser censurável, portanto, está voltada a motivos que vão além da justiça e da igualdade. Outro exemplo citado pelo autor nesse capítulo é da escolha do sexo em bebês: o descarte de embriões e a discriminação sexual como ocorrem na China e na Índia, contra meninas. Permanece algo de inquietante em relação não só aos meios, mas aos fins almejados.

No segundo capítulo, analisa nossa resposta moral ao melhoramento, isto é, não haveria mais dedicação e talento. Significa que daríamos mais importância ao farmacêutico do

\begin{tabular}{|c|c|c|c|c|c|}
\hline intuitio & $\begin{array}{c}\text { ISSN } \\
1983-4012\end{array}$ & Porto Alegre & Vol.8 $-\mathrm{N}^{\circ} .1$ & $\begin{array}{c}\text { Junho } \\
2015\end{array}$ & p.317-324 \\
\hline
\end{tabular}


que ao jogador, por exemplo, uma vez que treinamento e disciplina não teriam mais importância, mas sim, o melhoramento genético a que foi submetido o atleta. O problema estaria no que Sandel chama de "superoperação, uma aspiração prometeica de remodelar a natureza, incluindo a natureza humana, para servir aos nossos propósitos e satisfazer os nossos desejos (pag.40)”. Não haveria mais dádiva na natureza humana. Reconhecer que a vida é uma dádiva é reconhecer que nossos talentos não são mérito unicamente nosso. Isso nos conduz a humildade e, apesar de parecer religioso, tem efeitos para além da religião. Entretanto, tem-se percebido diversas formas de "alterar" atletas sem esteroides ou qualquer outro medicamento ou mesmo sem modificações genéticas. Os casos apresentados pelo autor são a dieta hipercalórica para ganho de peso de alguns jogadores de futebol americano e da casa da Nike nos EUA, que possui oxigênio limitado, a fim de simular grandes altitudes e aumentar, desta forma, a produção de glóbulos vermelhos nos atletas. Esse aumento os tornaria mais aptos à corrida, uma vez que estariam acostumando seu corpo a reduzida oxigenação. Desse ponto, faz uma análise sob duas perspectivas: se por um lado considerarmos o esporte como sendo uma disputa de talentos, este ficaria prejudicado com as modificações genéticas. Entretanto, por outro, se fosse apenas um entretenimento, em que regras são pouco importantes e o que faz a diferença é a quantidade de público que atraem, poderia ficar beneficiado caso atraísse mais pessoas. Porém, é óbvio que o esporte evidencia uma disputa de talentos e que se fosse apenas um passatempo, não existiriam regras nem torcida e, tampouco, disputa admirada pelos espectadores. Os jogadores seriam nivelados, de certa forma, pela engenharia genética.

Em Filhos projetados, pais projetistas fica evidente a intenção do autor em demonstrar o lado perturbador da eugenia. Para ele, os filhos sempre foram dádivas e merecedores de amor incondicional dos pais. $\mathrm{O}$ amor destinado aos filhos nunca foi dependente das qualidades e talentos que estes por ventura pudesse possuir ou vir a adquirir. Não escolhemos, em suma, nossos filhos e, tampouco, seu futuro. Entretanto, há pelo menos uma década, os pais resolveram se tornar maestros da vida dos filhos. Além de exercer sua função natural de educadores, interferem de modo pontual na vida destes: matriculam nas melhores escolas, em alguma atividade esportiva, em aulas de balé, contratam professores particulares e inclusive, encaminham a curso pré-vestibular para que possam frequentar as melhores universidades. O autor aponta que nos Estados Unidos os administradores de faculdades precisam ser treinados para controlar pais dominadores que chegam a fazer as monografias dos filhos e dormir em

\begin{tabular}{|c|c|c|c|c|c|}
\hline intuitio & $\begin{array}{c}\text { ISSN } \\
1983-4012\end{array}$ & Porto Alegre & Vol.8 $-\mathrm{N}^{\circ} .1$ & $\begin{array}{c}\text { Junho } \\
2015\end{array}$ & p.317-324 \\
\hline
\end{tabular}


conjuntos habitacionais estudantis para averiguar exatamente como os filhos estão se portando. Outro apontamento é o uso excessivo de medicamentos como a Ritalina. Tal medicamento que anteriormente era utilizado apenas para tratar distúrbios de déficit de atenção, hoje, é utilizado em pessoas perfeitamente saudáveis para aumentar sua concentração. É claro que o amor incondicional não impede que os pais moldem e dirijam a vida de seus filhos de modo a desenvolvê-los da melhor maneira possível. Por isso, a pergunta central deste capítulo é: Qual a diferença em oferecer ajuda aos filhos por meio da educação e da disciplina e fornecê-la por meio do melhoramento genético? A diferença, segundo o autor, reside no fato de que os pais que desejam melhorar os filhos tendem a exagerar e a converter os mesmos em produtos da sua vontade ou instrumentos de sua ambição: pais alucinados por algum tipo de esporte acabam determinados a transformar os filhos em campeões. Há, também, aqueles que pré-determinam a profissão da criança. O autor termina o capítulo com a opinião de que no campo da moral a eugenia e a educação fornecida por pais ansiosos em moldar seus filhos não possuem grande distanciamento. Ao mesmo tempo, porém, não devemos abraçar, por isso, a eugenia. Devemos, sim, questionar essa dominação dos pais que deixa de lado o sentido de dádiva da vida.

A velha e a nova eugenias demonstra que não há grande diferença entre o que se pensava e o que se pensa hoje em termos de engenharia genética. Primeiramente cabe destacar que o termo "eugenia" foi criado pelo cientista Francis Galton com o sentido de bem nascido. Este entendia que o principal papel da racionalidade era o aprimoramento da raça humana e que esta ideia deveria ser uma nova religião. Em nome disso, inúmeras pessoas (para catalogar e coletar dados) foram encaminhadas a prisões, hospitais, asilos e sanatórios e juntamente com outras que já se encontravam nesses lugares, após serem consideradas defeituosas, foram esterilizadas. Destaca-se que em 1927 a Suprema Corte dos Estados Unidos defendeu a constitucionalidade das leis de esterilização dos mais diversos Estados do país em nome da não propagação de uma raça de manifestamente inadequados. Da mesma forma, em 1933, quando conquistou o poder, Adolf Hitler promulgou uma lei de esterilização na Alemanha sobre a qual orgulhosamente se manifestou em Mein Kampf (Minha Luta). Contudo, como se sabe, a eugenia alemã foi muito além da esterilização, com assassinatos em massa. Em momento mais recente, por volta de 1980, o governo de Cingapura ofertava dinheiro às famílias pobres que se submetessem a esterilização e estimulava, ao mesmo tempo, mulheres de nível universitário a terem mais filhos. Isso tudo em nome da preservação dos padrões de educação. Apenas a título de

\begin{tabular}{|c|c|c|c|c|c|}
\hline intuitio & $\begin{array}{c}\text { ISSN } \\
1983-4012\end{array}$ & Porto Alegre & Vol.8 $-\mathrm{N}^{\circ} .1$ & $\begin{array}{c}\text { Junho } \\
2015\end{array}$ & p.317-324 \\
\hline
\end{tabular}


curiosidade, somente em 2003 (após reportagens investigativas) os americanos fizeram pedidos formais de desculpas aos esterilizados compulsoriamente. Assim, o termo eugenia, no passado, passou a ter um aspecto repugnante. Hoje, não está mais ligada ao Estado, mas as ambições humanas e, consequentemente, ao comércio de gens. Pais podem comprar óvulos e espermatozoides com características genéticas que desejam para os filhos e proceder a uma inseminação artificial, sem qualquer coerção. Isso demonstra que não era a coerção do Estado o único problema. Com a liberdade de escolha, as intenções eugênicas do passado não foram deixadas de lado o que provoca um mal-estar social. Os bancos de semên catalogam apenas doadores com características exigidas pelos clientes, entre elas, formação universitária. Claro, há biótipos determinados também. Assim, o discurso sobre a biotecnologia vem sendo revivido principalmente no que diz respeito a uma eugenia liberal. Geneticistas, atualmente, acreditam que se os melhoramentos foram distribuídos de modo igualitário, as medidas eugênicas não são censuráveis e sim, moralmente necessárias. Para endossar essa ideia o autor cita John Rawls (Teoria da Justiça) e Ronald Dworkin (Playing God: Genes, Clones and Luck). A diferença primordial entre a eugenia do passado e a atual está no individualismo. Antes se tinha um Estado autoritário e disposto a melhorar a sociedade como um todo e com métodos discutíveis, é claro. Hoje, trata-se de pais abonados financeiramente e dispostos a pagar quantias altas para terem filhos conforme desejam e armá-los para uma sociedade competitiva. O autor destaca que os eugenistas liberais, em sua maioria, defendem, também, que essas modificações devem deixar em aberto o futuro dessas crianças, ou seja, não podem determinar carreiras ou modos de vida. Embora com defensores de peso já citados anteriormente, é trazido á baila um importante filósofo alemão contrário a essa permissividade. Trata-se de Jürgen Habermas. Sandel informa que na teoria de Habermas a eugenia liberal não pode ser permitida uma vez que desconsidera conceitos espirituais e teológicos, além da autonomia e da liberdade - não depende de nenhuma concepção particular de bem viver. Prejudicaria a autonomia uma vez que esses indivíduos não seriam autores da própria história e, quanto à liberdade, na medida em que destrói relações simétricas entre seres humanos livres e iguais. Termina esse capítulo informando que a teoria de Habermas é muito mais profunda, pois leva em conta, ainda, talentos adquiridos e conquistas humanas, bem como a postura dos pais diante do mundo e suas atitudes de dominação dos filhos.

No último capítulo, Domínio e Talento as questões centrais são a humildade, responsabilidade e solidariedade diante da possibilidade da biotecnologia dissolver nosso senso

\begin{tabular}{|c|c|c|c|c|c|}
\hline intuitio & $\begin{array}{c}\text { ISSN } \\
1983-4012\end{array}$ & Porto Alegre & Vol.8 $-\mathrm{N}^{\circ} .1$ & $\begin{array}{c}\text { Junho } \\
2015\end{array}$ & p.317-324 \\
\hline
\end{tabular}


de dádiva em relação à vida. Sob a ótica da religião, quando não compreendemos que nossos talentos e nossas potências não se devem unicamente a nós mesmos é não compreender nosso lugar na criação e confundir nosso papel com o de Deus. Mas não é só sob o ponto de vista da religião que podemos descrever nossa relação com a humildade, com a responsabilidade e com a solidariedade. Em um mundo social, que preza o domínio e o controle, a experiência de ser pai ou mãe é uma escola de humildade já que não podemos escolher os filhos que teremos. Essa, também seria diminuída ao passo que nos acostumaríamos ao auto melhoramento genético. Quanto à responsabilidade, seríamos mais responsáveis à medida que escolhemos ou deixamos de escolher determinadas características: mestres de nossas cargas genéticas, maior o fardo que carregaremos em relação às qualidades que não possuímos. Isso, paradoxalmente, poderá reduzir nosso grau de solidariedade com os mais carentes. O autor aponta como exemplo os planos de saúde. Os saudáveis acabam subsidiando os doentes uma vez que unem seus recursos e riscos. Isso só acontece porque as pessoas não conhecem nem controlam os próprios fatores de riscos. Se conhecessem, provavelmente não nutririam qualquer sentimento moral que a solidariedade social requer. Os bem-sucedidos não sustentariam a noção de dádiva (que nenhum de nós é completamente responsável pelo próprio sucesso) que os "premiou" e não sentiriam qualquer responsabilidade moral em relação aos menos afortunados na loteria genética. Por se tratar do último capítulo, o autor defende seus argumentos contra o melhoramento genético pressupondo as objeções que outros autores poderiam fazer a esses argumentos. Em relação a vida ser uma dádiva, explicita que não há necessariamente um questão religiosa relacionada, pois embora alguns creiam que Deus é o responsável pela nossa vida, não é preciso acreditar nele para valorizar a vida e reverenciá-la. Podemos compreender a vida como um direito inalienável e inviolável sem, necessariamente, abraçar os conceitos de santidade desta. Após, Sandel argumenta que não deseja provar que o custo da biotecnologia é maior que o benefício. Apenas acredita na ponderação uma vez que as modificações genéticas são aparentemente uma forma de dominar a nós mesmo para nos encaixar no mundo. Isso não é autonomia, é apenas contemplar nossa vontade. Além disso, poderá significar um retrocesso uma vez que após décadas o homem percebeu que não precisa dominar a natureza, apenas juntar-se a ela, como parte dela.

Para finalizar, no epílogo cujo título inicial refere-se à ética embrionária, o autor justifica-se no sentido de que há diferença entre curar e melhorar. Defende a pesquisa com células-tronco para a cura de doenças, argumentando que nem tudo que nos é dado é uma dádiva e que para a cura de

\begin{tabular}{|c|c|c|c|c|c|}
\hline intuitio & $\begin{array}{c}\text { ISSN } \\
1983-4012\end{array}$ & Porto Alegre & Vol.8 $-\mathrm{N}^{\circ} .1$ & $\begin{array}{c}\text { Junho } \\
2015\end{array}$ & p.317-324 \\
\hline
\end{tabular}


determinadas doenças se faz necessária tal manipulação de genes. Nesse sentindo, não seria uma conduta antiética. Porém, tal questão retoma antigas discussões sobre a existência ou não de vida neste estágio do embrião. Além disso, questiona-se a existência de diferença na conduta humana: se esses embriões fossem excedentes e descartados de tratamentos para infertilidade ou se fossem clones, a conduta humana na pesquisa seria eticamente louvável? O projeto de lei sobre células tronco votado pelo Congresso americano (vetado por Bush em 2006) fazia distinção e só permitiria pesquisas com embriões excedentes de tratamentos de infertilidade. Aparentemente essa distinção parece moralmente defensável, mas não se sustenta sob o ponto de vista de que não deveria haver embriões excedentes (na Alemanha há lei que proíbe os médicos de fertilizarem óvulos que não serão implantados). Destaca-se que para fins de pesquisa o embrião acaba por ser destruído na fase de blastócito (células das quais se pode reproduzir tecidos humanos). Assim, parece-nos um tanto mórbido, ao menos, criar vidas humanas para destruí-las com o único propósito de explorá-las. Alguns senadores americanos, na época justificavam seus votos desfavoráveis afirmando que não se pode considerar aceitável matar deliberadamente um ser humano para ajudar outro. Porém, os que são a favor da pesquisa argumentam que a fecundação in vitro (FIV) produz inúmeros embriões excedentes para aumentar as probabilidades de uma gravidez bem sucedida já sabendo que vários serão descartados. Então, se poderia utilizar esses excedentes, que teoricamente serão descartados, para salvar vidas. Segundo dados trazidos pelo autor, um estudo recente revelou que 400 mil embriões congelados estão definhado nos Estados Unidos. Assim, uma vez que esses embriões já existem não haveria nada a perder. Entretanto, quanto ao embrião clone ou ao excedente, como bem argumenta o autor, não há diferença. Se considerarmos antiética a destruição de embriões excedentes para fins de pesquisa por já haver vida, da mesma forma temos que considerar na clonagem. Não há como fazer diferença sobre este aspecto uma vez que o cerne da questão é a existência de vida na fase em que são destruídos os embriões. Para a argumentação de Sandel, blastócitos são apenas células e não um bebê propriamente dito, considerando falha a crença religiosa de que a alma surge no momento da concepção e que a vida humana é inviolável desde essa mesma concepção já que não há uma linha para delimitar o início da personalidade. Para ele o blastócito e como uma célula epitelial, ninguém negaria que é humana e viva, mas também, ninguém tentaria argumentar que se trata de um ser humano propriamente dito. Sustenta que o fato de toda a pessoa ter sido um dia um embrião não prova que o embrião é pessoa, são apenas seres humanos em potencial. A vida

\begin{tabular}{|c|c|c|c|c|c|}
\hline intuitio & $\begin{array}{c}\text { ISSN } \\
1983-4012\end{array}$ & Porto Alegre & Vol.8 $-\mathrm{N}^{\circ} .1$ & $\begin{array}{c}\text { Junho } \\
2015\end{array}$ & p.317-324 \\
\hline
\end{tabular}


humana se desenvolve em níveis. $\mathrm{O}$ fato de haver um desenvolvimento contínuo que transforma o blastócito em embrião, este em feto e, finalmente, em recém-nascido não determinaria que um bebê e um blastócito fossem, no sentido moral, equivalentes. Na verdade, se estivéssemos convencidos de que são equivalentes, proibiríamos as pesquisas com células-tronco e baniríamos tratamentos de fertilidade que produzem e descartam embriões excedentes, tratando como assassinato e sujeitando os cientistas à punição criminal. Outro argumento do autor é o de que muitos embriões são perdidos durante uma gestação natural, ou por aborto ou por não conseguir se fixar no útero e em nenhum desses casos a religião (maior defensora da vida incipiente) prega que se façam os rituais funerários que se fariam para a morte de um bebê. Deixa claro, entretanto, que os embriões não são objetos ao nosso dispor. Devem ser respeitados como vida em potencial, só não devem ser considerados pessoas. Para ele não devemos partir da alegação kantiana de que o universo moral se divide em termos binários: tudo é pessoa ou coisa. Afirma, ainda, que a pesquisa com células-tronco voltada para a cura de doenças debilitantes é um exercício nobre do engenho humano para promover a cura e desempenhar nosso papel de reparar o mundo dado. A única ressalva é a necessidade de leis que regulamentem essas pesquisas para tornar o progresso da biomedicina uma bênção para a saúde e frear o uso descontrolado da vida humana.

\section{Referências}

SANDEL, Michael J. Contra a perfeição: Ética na era da engenharia genetica. (trad. Ana Carolina Mesquita). Rio de Janeiro: Civilização Brasileira, 2013, 160 páginas.

Recebido em: 04/09/2014

Aprovado para publicação em: 05/05/2015

\begin{tabular}{|c|c|c|c|c|c|}
\hline intuitio & $\begin{array}{c}\text { ISSN } \\
1983-4012\end{array}$ & Porto Alegre & Vol.8 $-\mathrm{N}^{\circ} .1$ & $\begin{array}{c}\text { Junho } \\
2015\end{array}$ & p.317-324 \\
\hline
\end{tabular}

